\title{
High Refractive Index Materials of Iron Sulfides and Poly(ethylene oxide)
}

\section{Journal Article}

Author(s):

Kyprianidou-Leodidou, Tasoula; Althaus, Hans-Jörg; Wyser, Yves; Vetter, Daniel; Büchler, Michele; Caseri, Walter; Suter, Ulrich W. (iD)

Publication date:

1997

Permanent link:

https://doi.org/10.3929/ethz-b-000422822

Rights / license:

In Copyright - Non-Commercial Use Permitted

Originally published in:

Journal of Materials Research 12(8), https://doi.org/10.1557/JMR.1997.0294 


\section{High refractive index materials of iron sulfides and poly(ethylene oxide)}

Tasoula Kyprianidou-Leodidou, Hans-Jörg Althaus, Yves Wyser, Daniel Vetter, Michele Büchler, Walter Caseri, and Ulrich W. Suter

Eidgenössische Technische Hochschule, Institut für Polymere, ETH-Zentrum, CH-8092 Zürich, Switzerland and Eidgenössische Materialprüfungsund Forschungsanstalt, Abt. 136, CH-8600 Dübendorf, Switzerland

(Received 15 December 1994; accepted 10 April 1996)

High refractive index composites of iron sulfides and poly(ethylene oxide) (PEO) have been prepared by co-precipitation from aqueous solution. Several reaction parameters were varied: inorganic reactants, reactant ratios, reaction temperatures, and reaction times. Selected samples were characterized with organic microelemental analysis, x-ray fluorescence spectroscopy, x-ray diffraction, DSC, and TEM. The nanocomposites with the highest refractive indices have been prepared using PEO, Mohr's salt, and $\mathrm{H}_{2} \mathrm{~S}$ or NaHS. The analyses indicate that the iron sulfides in these materials consist of finely dispersed mackinawite and greigite ("amorphous" $\mathrm{FeS}$ ) and, partially, also pyrite. The refractive indexes of the resulting composites are clearly above 2 at 632.8 and $1295 \mathrm{~nm}$ and can assume values between 2.5 and 2.8.

\section{INTRODUCTION}

Composites of polymers and inorganic substances are widely used to obtain materials with advantageous properties of both materials classes. Polymers are, e.g., readily processed while inorganic materials possess physical properties unattainable with polymers. One of these properties is an extreme refractive index. The refractive index of organic compounds, including organic polymers, is usually in a range of $1.3-1.7 .^{1,2}$ In contrast, the refractive index of inorganic materials varies in a much wider range. ${ }^{1,3}$ For example, the refractive index of gold is $0.2-0.4$ and that of $\mathrm{PbS}$ is above 4, each in a broad wavelength range.

Nanocomposites with extremely high or low refractive index have been prepared recently by coprecipitation or spin-coating from aqueous solutions. ${ }^{4-7}$ The high refractive index nanocomposites consist of colloidal lead sulfide embedded in a polymer matrix. Due to the high refractive index of $\mathrm{PbS}$, that of the composites is up to 3 , over a broad wavelength range, and to our knowledge by far the highest reported for a polymer composite. However, the high lead content precludes the use of such materials in many applications (e.g., solar cells ${ }^{8,9}$ ), and an environmentally more benign substance than lead sulfide is required.

Iron sulfides might also be suitable inorganic components for high refractive index nanocomposites. For example, we measured the refractive index of a block of a Spanish pyrite crystal and obtained values above 3.5 at 632.8 and $1295 \mathrm{~nm}$ (an exact value cannot be given because of possible structural imperfections in the crystal surface region and, in particular, surface impurities). However, the chemistry of iron sulfides is complex.
Considerable interest has been concentrated in the mechanisms of the formation of iron sulfides in sediments, especially the formation of pyrite. ${ }^{10,11}$ An iron-sulfur system can produce, depending on the experimental conditions, various iron sulfides such as "amorphous FeS", greigite $\left(\mathrm{Fe}_{3} \mathrm{~S}_{4}\right)$, mackinawite $\left(\mathrm{FeS}_{1-x}\right)$, pyrrhotite $\left(\mathrm{Fe}_{1-x} \mathrm{~S}\right)$, marcasite $\left(\mathrm{FeS}_{2}\right.$, orthorhombic), pyrite $\left(\mathrm{FeS}_{2}\right.$, cubic), and troilite (FeS). ${ }^{12}$ These phases are the most common components of sedimentary iron sulfide minerals with "amorphous FeS" being the main component. ${ }^{13}$ The number of different iron sulfides in a reaction mixture can be considerably reduced by control of the reaction conditions leading to the formation of an optimum product. ${ }^{12}$ Variations of stoichiometry, temperature, and iron salt used for the synthesis of iron sulfides can cause a dramatic change in the product composition. ${ }^{14,15}$

Some controversy exists in the literature about the nature of "amorphous FeS." Berner attributed it to a mixture of fine-grained greigite and mackinawite and found it to be amorphous by $\mathrm{x}$-ray diffraction analysis. ${ }^{14}$ Rickard found characteristic x-ray diffraction peaks of mackinawite in "amorphous FeS" and suggested that "amorphous FeS" may not be distinct from mackinawite. ${ }^{16}$

Mackinawite is a tetragonal sulfur-deficient iron(II) sulfide $\left(\mathrm{FeS}_{1-x}\right) .{ }^{12}$ Like "amorphous FeS" and greigite, it is soluble in hot $\mathrm{HCl}$ in contrast to pyrite. ${ }^{17}$ Mackinawite, greigite, and "amorphous FeS" are also often considered as metastable iron sulfides since in the presence of $\mathrm{HS}^{-}$and at concentrations above pyrite saturation they transform to pyrite. ${ }^{13,18}$ Mackinawite is the most frequent product of the low temperature precipitation of ferrous ions by $\mathrm{H}_{2} \mathrm{~S}$ or salts such as $\mathrm{NaHS}$ and $\mathrm{Na}_{2} \mathrm{~S}$ 
(below $100{ }^{\circ} \mathrm{C}$ ) in the absence of oxidants. ${ }^{12}$ A possible mechanism of mackinawite formation is the following ${ }^{15}$ :

$$
\begin{gathered}
\mathrm{Fe}^{2+}+\mathrm{SH}^{-} \rightarrow \mathrm{FeSH}^{+} \\
2 \mathrm{FeSH}^{+} \rightarrow \mathrm{Fe}_{2} \mathrm{~S}_{2}+2 \mathrm{H}^{+} \\
n \mathrm{Fe}_{2} \mathrm{~S}_{2} \rightarrow \text { mackinawite. }
\end{gathered}
$$

According to the above mechanism, nucleation proceeds by complexation of $\mathrm{Fe}^{2+}$ and $\mathrm{SH}^{-}$and subsequent dimerization of $\mathrm{FeSH}^{+}$with elimination of protons. Association of the dimer ("polymerization") leads to the layered structure of mackinawite. ${ }^{15}$

There is broad agreement in the literature that greigite is formed after partial oxidation of mackinawite. ${ }^{19}$ Thus mackinawite is a required precursor for the formation of greigite. ${ }^{19-21} \mathrm{~A}$ mechanism suggested for the transformation of mackinawite to greigite is the following ${ }^{19}$ :

$$
\begin{gathered}
3 \mathrm{FeS}_{1-x}+2 \mathrm{O}_{2} \rightarrow \mathrm{Fe}_{3} \mathrm{O}_{4}+\left(\frac{3-3 x}{8}\right) \mathrm{S}_{8} \\
3 \mathrm{FeS}_{1-x}+\left(\frac{1+3 x}{8}\right) \mathrm{S}_{8} \rightarrow \mathrm{Fe}_{3} \mathrm{~S}_{4} .
\end{gathered}
$$

Pyrite and marcasite formation is connected with the conversion of iron(II) monosulfide precursors to iron disulfides through different possible reactions with sulfur sources. ${ }^{22,23}$ The formation of pyrite and marcasite through a nucleation-growth process has also been suggested but is considered less favorable, especially at temperatures below $100{ }^{\circ} \mathrm{C} .{ }^{22,24,25}$ The most probable mechanism of disulfide formation is the slow reaction of iron sulfide with elemental sulfur at elevated temperatures in the absence of oxygen. ${ }^{17,26}$

Pyrite is the only reaction product of aqueous $\mathrm{H}_{2} \mathrm{~S}$ with iron, troilite $(\mathrm{FeS})$, or mackinawite at $100-160{ }^{\circ} \mathrm{C}$, in the absence of oxidants other than $\mathrm{H}_{2} \mathrm{~S} .{ }^{15}$ Marcasite is abundantly produced only under acidic conditions. ${ }^{27}$ In the presence of oxygen or sulfur, or when an anodic current is applied at the crystallization site, marcasite is formed together with pyrite. ${ }^{15}$ From the analysis of both pyrite and marcasite, iron-to-sulfur ratios different from the "ideal" value of 2 have been reported. ${ }^{13}$ This is probably due to the presence of impurities.

This study deals with the possible variables that could affect the formation of iron sulfides in poly(ethylene oxide) nanocomposites. The products with the highest refractive indices were characterized in more detail.

\section{EXPERIMENTAL}

\section{A. Preparation of the nanocomposites: Chemicals}

The chemicals were purchased from the following companies: poly(ethylene oxide) (PEO) $\left(M_{w}=5 \cdot 10^{6}\right)$ from Aldrich (No. 18, 9472), $\mathrm{FeSO}_{4} \cdot 7 \mathrm{H}_{2} \mathrm{O}$ from Fluka (No. 44970), $\mathrm{FeCl}_{2} \cdot 4 \mathrm{H}_{2} \mathrm{O}$ from Fluka (No. 44939), $\left(\mathrm{NH}_{4}\right)_{2} \mathrm{Fe}\left(\mathrm{SO}_{4}\right)_{2} \cdot 6 \mathrm{H}_{2} \mathrm{O}$ (Mohr's salt) from Aldrich (No. 21, 540-6), NaHS from Aldrich (No. 16,152-7), and $\mathrm{H}_{2} \mathrm{~S}$ from Pangas.

\section{B. Preparation of composites using $\mathrm{H}_{2} \mathrm{~S}$ or NaHS}

In a typical experiment $0.03 \mathrm{~mol}$ of an iron(II) salt was dissolved in $50 \mathrm{ml}$ of a $0.25 \% \mathrm{w} / \mathrm{v}$ aqueous PEO solution. The solution was poured in a double-neck flask connected with an $\mathrm{H}_{2} \mathrm{~S}$ bottle. To obtain the $\mathrm{NaOH} / \mathrm{Fe}$ ratios indicated in the text, the corresponding volume of an $8 \mathrm{~N}$ solution of $\mathrm{NaOH}$ was added under strong stirring. The closed system was put under an overpressure of 0.3 bar of $\mathrm{H}_{2} \mathrm{~S}$ for $35 \mathrm{~min}$ (in some experiments a solution of NaHS as the sulfur source was employed instead, or elemental sulfur was previously added, see below). The $\mathrm{H}_{2} \mathrm{~S}$ supply was stopped and the flask was immersed in an oil bath of the temperature indicated in the text. After $15 \mathrm{~min}$ at elevated temperature, the reaction solution was again treated with 0.3 bar of $\mathrm{H}_{2} \mathrm{~S}$ for 10 min. The treatment with $\mathrm{H}_{2} \mathrm{~S}$ was repeated twice a day.

At the end of each experiment, the suspension was filtered in a Buchner funnel (por. 4) and rinsed with warm water. The filtrate was dried at ca. $100 \mathrm{mbar}$ and $65{ }^{\circ} \mathrm{C}$ overnight. The $\mathrm{pH}$ of the filtrate was $7-8$ (estimated by indicator paper). The produced powder was ground in a mortar to enhance homogeneity. Pellets were produced by pressing powder for $15 \mathrm{~min}$ at a pressure of 125 bar with a Perkin-Elmer press.

\section{Preparation of composites using $\mathrm{Na}_{2} \mathrm{~S}$}

In a typical experiment $10 \mathrm{ml}$ of a $0.6 \mathrm{M} \mathrm{FeCl}_{2}$ solution were added to $10 \mathrm{ml}$ of a $0.1 \mathrm{M}$ PEO solution containing an amount of $\mathrm{Na}_{2} \mathrm{~S}$ equimolar to $\mathrm{FeCl}_{2}$ (different PEO fractions as indicated in text were obtained by changing the $\mathrm{FeCl}_{2}$ and $\mathrm{Na}_{2} \mathrm{~S}$ concentrations). A black substance precipitated immediately. The material was filtered, washed with water, and finally dried at a pressure of ca. 0.001 mbar. The produced powder was ground in a mortar to enhance homogeneity. Pellets were produced by pressing powder for $15 \mathrm{~min}$ at a pressure of 125 bar with a Perkin-Elmer press.

\section{Preparation of " $\mathrm{Na}_{2} \mathrm{~S}_{4}$ "}

A double-neck flask equipped with a reflux condenser was filled with nitrogen, and $3.262 \mathrm{~g}(0.102 \mathrm{~mol})$ 
of sulfur and $200 \mathrm{ml}$ of toluene (distilled over $\mathrm{CaH}_{2}$ ) were placed in the flask under nitrogen flooding. The temperature was elevated to $120{ }^{\circ} \mathrm{C}$ (the elemental sulfur completely dissolved at $108{ }^{\circ} \mathrm{C}$ ), and $0.996 \mathrm{~g}$ $(0.0433 \mathrm{~mol})$ of sodium was added in portions to the slightly yellow solution. Upon addition of sodium, the solution strongly boiled. After stirring at $120{ }^{\circ} \mathrm{C}$ for $1.5 \mathrm{~h}$, the solution was cooled to room temperature and $5 \mathrm{ml}$ of ethanol were added to react with excess sodium. The yellow-orange reaction product was filtered and washed with hot toluene to remove elemental sulfur that might not have reacted with sodium. The orange-yellow, hygroscopic, crystalline powder (yield $3.08 \mathrm{~g}$ ) was dried at $0.1 \mathrm{mbar}$ for $12 \mathrm{~h}$.

\section{E. Preparation of composites with $\mathrm{Na}_{2} \mathrm{~S}_{4}$}

$282.2 \mathrm{mg}$ of $\mathrm{FeCl}_{2} \cdot 4 \mathrm{H}_{2} \mathrm{O} \quad(1.42 \mathrm{mmol})$ were added to $50 \mathrm{ml}$ of a slowly stirred $0.1 \% \mathrm{w} / \mathrm{v}$ aqueous PEO solution. After a few minutes, the iron salt was dissolved. Then $201.3 \mathrm{mg}$ ( $1.15 \mathrm{mmol})$ of " $\mathrm{Na}_{2} \mathrm{~S}_{4}$ " were added under strong stirring. Instantaneously, a solid precipitated that was filtered and washed with $250 \mathrm{ml}$ water. The material was placed between dialysis membranes and several blotting papers and pressed with a $15 \mathrm{~kg}$ load for 1 day. The blotting paper was removed and the sample, still enclosed in the dialysis membrane, was exposed to air for 3 days. Pellets were produced by pressing powder for $15 \mathrm{~min}$ at a pressure of 125 bar with a Perkin-Elmer press.

\section{F. Analysis}

Elemental analysis for carbon and hydrogen was performed by the microanalytical service of the Laboratorium für Anorganische Chemie of the ETH Zürich. The PEO content in the nanocomposite material was calculated from the carbon content (PEO contains 54.53\% $\mathrm{w} / \mathrm{w}$ of carbon).

X-ray powder diffraction analyses were carried out on a Siemens Diffractometer D5000, with the use of $\mathrm{Cu} \mathrm{K}_{\alpha}$ radiation $(\lambda=1.5406 \AA$ ) from a $1.2 \mathrm{~kW}$ source.

Ellipsometric measurements were obtained on a Plasmos SD 2300 ellipsometer. Optical constants were measured at 10 different spots and five measurements were performed at each spot.

Thermal analyses (TGA and DSC) were carried out on a Perkin-Elmer Series 7 apparatus.

Transmission electron micrographs were obtained by the following procedure: Small amounts of nanocomposite material were embedded in a resin (Epon/Araldite) and hardened for at least $24 \mathrm{~h}$ at $60{ }^{\circ} \mathrm{C}$. The hardened resin specimens were cut to a thickness of $100 \mathrm{~nm}$ with a diamond knife on a Reichert Ultracut Microtome. The small pieces were collected on copper sieves and examined by a Philips EM301 microscope. TEM pictures were taken with an accelerating voltage of $80 \mathrm{kV}$ on Agfa Scientia 23D 56 cut film.

\section{RESULTS}

Nanocomposite materials of poly(ethylene oxide) (PEO) and iron sulfides were prepared by coprecipitation. $\mathrm{H}_{2} \mathrm{~S}, \mathrm{NaHS}$, or $\mathrm{Na}_{2} \mathrm{~S}$, or a sodium oligosulfide was added to an aqueous solution containing an iron salt and PEO. The polymer precipitated together with iron sulfides, and the resulting powder was dried and pressed.

\section{A. Composites prepared with PEO, $\mathrm{FeSO}_{4}$, and $\mathrm{H}_{2} \mathrm{~S}$}

The precipitation of the polymer was mostly quantitative. Here, the PEO fraction in the nanocomposites can be directed by the polymer content in solution, as demonstrated in Fig. 1 for composites prepared with $\mathrm{FeSO}_{4}$ and $\mathrm{H}_{2} \mathrm{~S}$ (reaction temperature $75{ }^{\circ} \mathrm{C}$, reaction time $20 \mathrm{~h}$ ). In this example the polymer content in the composite varies between 1.5 and $15 \% \mathrm{w} / \mathrm{w}$. Because the densities of iron sulfides are higher than that of PEO (see Discussion), the volume fraction of PEO in the above samples is estimated to fall from $4-5 \%$ and $30-40 \%$.

The refractive indices of all nanocomposites prepared from $\mathrm{FeSO}_{4}$ and $\mathrm{H}_{2} \mathrm{~S}$ (reaction temperature $75^{\circ} \mathrm{C}$, reaction time $20 \mathrm{~h}$ ) were about $2.0 \pm 0.2$ at $1295 \mathrm{~nm}$. Most samples were not suitable for refractive index measurements at $632.8 \mathrm{~nm}$, probably because the lower wavelength is more sensitive to surface roughness. ${ }^{7}$ For some samples, however, a refractive index could be obtained at $632.8 \mathrm{~nm}$, the values also being around 2.0.

Performing the experiments at room temperature, instead of $75^{\circ} \mathrm{C}$, for $20 \mathrm{~h}$ (composite I) or at $75{ }^{\circ} \mathrm{C}$ for $64 \mathrm{~h}$ (composite II) did not result in noteworthy changes of the refractive index. Composite I contained $2.9 \%$ and composite II, $1.6 \%$ PEO. X-ray diffraction

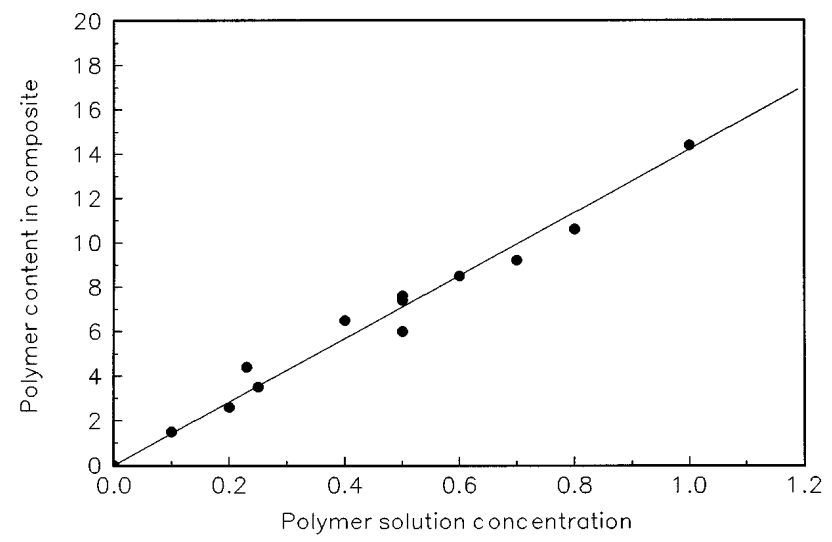

FIG. 1. PEO weight fraction in nanocomposites with iron sulfides versus the polymer content in solution for composites prepared with $\mathrm{FeSO}_{4}$ as an iron source (reaction time $20 \mathrm{~h}$ ). 
revealed elemental sulfur and troilite in composite I and elemental sulfur and greigite in composite II. In composite II, the $\mathrm{S} / \mathrm{Fe}$ ratio was $1.69 \pm 0.06$. Hence, if it is assumed that the inorganic fraction consists of greigite and elemental sulfur alone, composite II contained $8-11 \% \mathrm{w} / \mathrm{w}$ elemental sulfur.

It may be expected that the refractive index increases with increasing fraction of inorganic filler, ${ }^{5,7,28,29}$ and that it is, therefore, favorable to prepare composites with low polymer content, i.e., a polymer content just sufficient to obtain a "soft" material. However, the results do not show the expected refractive index dependence (within the experimental precision). This might be due to a different composition of the inorganic components in the composite or to an increased pore volume in the pressed samples with higher loadings of inorganic particles.

X-ray diffraction of four samples with different PEO loading revealed the presence of greigite, magnetite $\left(\mathrm{Fe}_{3} \mathrm{O}_{4}\right)$, and elemental sulfur. One sample also contained troilite. The presence of elemental sulfur was confirmed by DSC (see below). The x-ray measurements indicate, therefore, that the inorganic part of the different samples might have similar composition, but differences may occur. That the inorganic fraction is composed similarly, is supported by x-ray fluorescence spectroscopy. A $\mathrm{S} / \mathrm{Fe}$ ratio of 1.2 was found in all samples.

For two samples, the density of the precipitated powder particles was measured before pellet-pressing, for comparison with the density of the pressed samples used for the refractive index measurements. The density of a pressed sample with $4.1 \% \mathrm{w} / \mathrm{w}$ PEO (composite III) was $3.00 \mathrm{~g} / \mathrm{cm}^{3}$ compared to $3.16 \mathrm{~g} / \mathrm{cm}^{3}$ of the density of the powder particles, and the density of a pressed sample with $1.6 \% \mathrm{w} / \mathrm{w}$ PEO (composite II, see above) was $3.00 \mathrm{~g} / \mathrm{cm}^{3}$ compared with $3.53 \mathrm{~g} / \mathrm{cm}^{3}$ of the density of the powder particles. The density differences between pressed samples and powders suggest that the samples with 1.6 and $4.1 \% \mathrm{w} / \mathrm{w}$ (4 and 10\% v/v) PEO contained 15 and $5 \% \mathrm{v} / \mathrm{v}$ pores, respectively.

\section{B. Composites prepared with PEO, different iron salts, and $\mathrm{H}_{2} \mathrm{~S}$ or $\mathrm{NaHS}$}

Composites of PEO and iron sulfides were prepared at $75{ }^{\circ} \mathrm{C}$ under the same conditions with $\mathrm{H}_{2} \mathrm{~S}$ and $\left(\mathrm{NH}_{4}\right)_{2} \mathrm{Fe}\left(\mathrm{SO}_{4}\right)_{2} \cdot 6 \mathrm{H}_{2} \mathrm{O}$ (Mohr's salt), $\mathrm{FeSO}_{4}$, or $\mathrm{FeCl}_{2}$. The fraction of $\mathrm{PEO}$ in the nanocomposites was $3-4 \% \mathrm{w} / \mathrm{w}$, and the polymer precipitated quantitatively. The volume fraction of PEO is estimated to $7-12 \%$ (cf Discussion).

The refractive index of the resulting materials often increased when $\mathrm{NaOH}$ had been added to the iron salt solution. With Mohr's salt at a reaction temperature of $75{ }^{\circ} \mathrm{C}, 2.4$ eq $\mathrm{NaOH} / \mathrm{Fe}$ yielded higher refractive indices than $1.0,2.0,2.8$, or 4 eq, under our reaction conditions. The use of $\mathrm{FeCl}_{3} / \mathrm{NaOH}$ instead of iron(II) salts did not produce composites with higher refractive indices. As a consequence, the following experiments were performed with iron(II) salts and $2.4 \mathrm{eq} \mathrm{NaOH} / \mathrm{Fe}$, if not otherwise indicated.

The refractive indices of nanocomposites prepared with $\mathrm{H}_{2} \mathrm{~S}$ and various iron(II) salts in the presence of $\mathrm{NaOH}(2.4$ eq $\mathrm{NaOH} / \mathrm{Fe})$ are listed in Table I. The highest refractive index was measured for materials prepared from Mohr's salt and a reaction time of $93 \mathrm{~h}$. Few samples were suitable for refractive index measurements at $632.8 \mathrm{~nm}$. Refractive indices in the region of 2.3 were measured for the samples with the highest refractive indices; these samples had a dark brown color.

The crystalline components in the nanocomposites with the highest refractive indices consisted of mackinawite and greigite (Table I). A typical x-ray diffractogram of such a nanocomposite is shown in Fig. 2. All the samples prepared from $\mathrm{FeSO}_{4}$ and $\mathrm{FeCl}_{2}$ contained, among other components, also crystalline sulfur (see Table I); in addition, the samples prepared from $\mathrm{FeSO}_{4}$ contained pyrite. After $311 \mathrm{~h}$, all the samples showed the color of rust, indicating that a large fraction of the iron sulfides had decomposed to iron oxides. Using Mohr's salt, with $2.0 \mathrm{eq} \mathrm{NaOH} / \mathrm{Fe}$ the resulting nanocomposite material contained pyrite, sulfur, and $\mathrm{Fe}_{3} \mathrm{O}_{4}$, while with 2.8 eq the only crystalline component that could be detected was sulfur.

With $\mathrm{H}_{2} \mathrm{~S}$ and $2.4 \mathrm{eq} \mathrm{NaOH} / \mathrm{Fe}$, nanocomposites were prepared with Mohr's salt at reaction temperatures of 75 and $95{ }^{\circ} \mathrm{C}$. At a reaction temperature of $75{ }^{\circ} \mathrm{C}$, the refractive index of the nanocomposites increased with increasing reaction time up to a maximum after a few days and then decreased (Table II). The initial increase is most likely due to the formation of iron sulfides (mostly mackinawite). It seems that these sulfides decompose to iron oxides after longer heating periods. The refractive index of the involved iron oxides is lower than that of the iron sulfides, thus lowering the refractive index of the composite. At $95{ }^{\circ} \mathrm{C}$, the refractive index did not change significantly in the observed time intervals within the error limits. For reaction times below $100 \mathrm{~h}$, mackinawite was found in all samples prepared at 75 and $95{ }^{\circ} \mathrm{C}$. In addition, the samples prepared at $75{ }^{\circ} \mathrm{C}$ often contained greigite and those at $95{ }^{\circ} \mathrm{C}$ pyrite. Nanocomposite samples kept for 80 days at 0.001 mbar showed no significant changes in the optical constants and the composition of the crystalline phases, storing under vacuum prohibiting the formation of oxidation byproducts.

Using 2-6 eq NaHS/Fe instead of $\mathrm{H}_{2} \mathrm{~S}$ did not change the refractive indices considerably. Corresponding experiments were performed with Mohr's salt, $\mathrm{FeSO}_{4}$, and $\mathrm{FeCl}_{2}$ at 75 and $95{ }^{\circ} \mathrm{C}$ using $2.4 \mathrm{eq}$ 
TABLE I. Composition and optical constants $\left(n^{*}=n-i k\right)$ at $1295 \mathrm{~nm}$ of nanocomposites of poly(ethylene oxide) and iron sulfides, depending on the iron source and reaction time $t$ (for detailed experimental conditions, see text). The deviations from mean values refer to a confidence level of approximately $95 \%$.

\begin{tabular}{cllll}
\hline \hline$t$ & Iron source & $n$ & $k$ & Crystalline products \\
\hline $93 \mathrm{~h}$ & $\mathrm{FeSO}_{4}$ & $2.0 \pm 0.2$ & $-0.46 \pm 0.06$ & Pyrite, sulfur \\
& $\mathrm{FeCl}_{2}$ & $2.1 \pm 0.1$ & $-0.49 \pm 0.06$ & Greigite, mackinawite, sulfur, NaCl \\
& $\mathrm{Mohr}^{2}$ 's salt & $2.8 \pm 0.2$ & $-1.0 \pm 0.3$ & Greigite, mackinawite \\
& $\mathrm{FeSO}_{4}$ & $2.25 \pm 0.1$ & $-0.36 \pm 0.04$ & Greigite, pyrite, sulfur \\
& $\mathrm{FeCl}_{2}$ & $2.0 \pm 0.2$ & $-0.13 \pm 0.02$ & Erdite, sulfur, NaCl \\
& $\mathrm{Mohr's} \mathrm{salt}_{311 \mathrm{~h}}$ & $2.1 \pm 0.4$ & $-0.5 \pm 0.3$ & Mackinawite, sulfur, thenardite \\
& $\mathrm{FeSO}_{4}$ & $1.9 \pm 0.1$ & $-0.37 \pm 0.04$ & Greigite, pyrite, sulfur \\
& $\mathrm{FeCl}_{2}$ & $1.4 \pm 0.2$ & $-0.2 \pm 0.2$ & Pyrite, erdite, sulfur \\
& $\mathrm{Mohr}^{2}$ & $1.7 \pm 0.1$ & $-0.41 \pm 0.04$ & Pyrite, goethite, Fe $\mathrm{O}_{3}$ \\
\hline \hline
\end{tabular}

$\mathrm{NaOH} / \mathrm{Fe}$ (reaction times 50-100 h). The highest refractive indices were measured with Mohr's salt, and some of the results are displayed in Table III. Mackinawite was detected in all samples, in most cases accompanied by greigite. Also, the addition of elemental sulfur to samples prepared under different conditions $\left(\mathrm{FeCl}_{2}\right.$ or Mohr's salt, 75 or $95{ }^{\circ} \mathrm{C}, \mathrm{H}_{2} \mathrm{~S}$ or NaHS) with a reaction time of 70-90 h did not cause a significant change in refractive index (refractive indices in the range of 2.4-2.6 are obtained readily).

In some experiments, elemental sulfur was used in addition to $\mathrm{H}_{2} \mathrm{~S}$ because the growth of iron disulfides such as pyrite is enhanced in the presence of an excess of sulfur. The presence of sulfur in the reaction mixture did not change the refractive index of the resulting nanocomposites considerably. In other experiments, $\mathrm{FeCl}_{3}$ was taken as an iron source. With a $\mathrm{NaOH} / \mathrm{Fe}$ ratio of 3 and $\mathrm{H}_{2} \mathrm{~S}$ as sulfide source, refractive indices of 1.9 were measured at 632.8 and $1300 \mathrm{~nm}$.

The atomic ratio of sulfur to iron was between 0.95 and 1.28 in several samples with refractive indices between 2.4 and 2.8 (except for one sample, the measured ratios were above 1). All these samples were prepared with Mohr's salt and $\mathrm{NaOH} / \mathrm{Fe}=2.4$ under different experimental conditions (temperature 75 or $95{ }^{\circ} \mathrm{C}$; heat- ing time 48-140 h; $\mathrm{H}_{2} \mathrm{~S}$, NaHS, addition of elemental sulfur). All the samples contained mostly mackinawite, but also greigite and occasionally pyrite. No elemental sulfur was detected in any of these samples. For pyrite, a $\mathrm{S} / \mathrm{Fe}$ ratio of 2, for greigite a ratio of 1.33 , and for mackinawite a ratio somewhat below 1 is expected; hence, the measured $\mathrm{S} / \mathrm{Fe}$ ratios indicate that pyrite is not the main component in any of the samples, and that mackinawite is not the only iron sulfide in the composite. The results are in agreement with the assumption that mackinawite and greigite are the main inorganic components in the samples with the highest refractive indices, as revealed by x-ray diffraction analysis (Fig. 2).

The TEM pictures of these high refractive index materials did not show any well-formed crystalline structures but a rather "amorphous" phase (Fig. 3). As mentioned previously, Berner suggested that the "amorphous" phase found in many iron sulfide systems consisted mainly of a mixture of finely divided greigite and mackinawite which do not show characteristic peaks in x-ray diffraction analysis, ${ }^{14}$ while Rickard found characteristic mackinawite peaks in the x-ray diffraction analysis of the "amorphous" phase and conjectured it to consist mainly of mackinawite. ${ }^{16}$ Hence, the transmission electron micrographs are in agreement with

TABLE II. Composition and optical constants $\left(n^{*}=n-i k\right)$ of nanocomposites of poly(ethylene oxide) and iron sulfides at $1295 \mathrm{~nm}$, prepared from Mohr's salt and $\mathrm{H}_{2} \mathrm{~S}$, depending on the reaction time $t$ and reaction temperature $T$ (for detailed experimental conditions, see text). The deviation from the mean value refers to a $95 \%$ confidence level.

\begin{tabular}{|c|c|c|c|c|c|}
\hline$T$ & $t$ & & $n$ & $k$ & Crystalline products \\
\hline \multirow[t]{5}{*}{$75{ }^{\circ} \mathrm{C}$} & $20 \mathrm{~h}$ & 2.0 & \pm 0.2 & $-0.4 \pm 0.1$ & Mackinawite, pyrite, sulfur \\
\hline & $63 \mathrm{~h}$ & 2.3 & \pm 0.2 & $-0.9 \pm 0.2$ & Mackinawite, greigite, thenardite \\
\hline & $93 \mathrm{~h}$ & 2.8 & \pm 0.1 & $-1.1 \pm 0.3$ & Mackinawite, greigite \\
\hline & $164 \mathrm{~h}$ & 2.1 & \pm 0.4 & $-0.5 \pm 0.3$ & Mackinawite, thenardite, sulfur \\
\hline & $311 \mathrm{~h}$ & 1.7 & \pm 0.1 & $-0.41 \pm 0.04$ & Pyrite, geothite, $\mathrm{Fe}_{2} \mathrm{O}_{3}$ \\
\hline \multirow[t]{4}{*}{$95{ }^{\circ} \mathrm{C}$} & $26 \mathrm{~h}$ & 2.4 & \pm 0.1 & $-0.8 \pm 0.2$ & Mackinawite, pyrrhotite, $\mathrm{Na}_{2} \mathrm{Fe}\left(\mathrm{SO}_{4}\right)_{2}$ \\
\hline & $48 \mathrm{~h}$ & 2.5 & \pm 0.2 & $-0.8 \pm 0.2$ & Mackinawite, greigite, pyrite \\
\hline & $70 \mathrm{~h}$ & 2.4 & \pm 0.3 & $-0.7 \pm 0.4$ & Mackinawite, greigite, pyrite \\
\hline & $96 \mathrm{~h}$ & 2.45 & \pm 0.08 & $-0.71 \pm 0.08$ & Mackinawite, pyrite \\
\hline
\end{tabular}




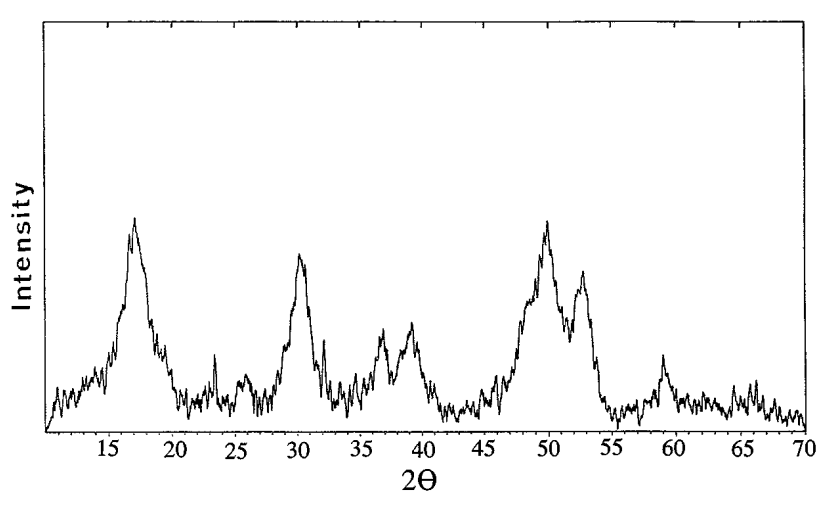

FIG. 2. A typical x-ray diffractogram of a nanocomposite, prepared from Mohr's salt and $\mathrm{H}_{2} \mathrm{~S}$ as the sulfur source, that consists of mackinawite and greigite.

the assumption that mackinawite and (maybe) greigite are the inorganic main products in the nanocomposites, but it cannot be excluded that the inorganic material consists mainly of "real" amorphous iron sulfides.

As mentioned above, some samples contained, in addition to mackinawite and greigite, pyrite. Figure 4 presents a characteristic x-ray diffractogram of such a sample (prepared at $95{ }^{\circ} \mathrm{C}$ for $48 \mathrm{~h}$ with $\mathrm{H}_{2} \mathrm{~S}$ and $\mathrm{NaOH} / \mathrm{Fe}=2.4$ ). The corresponding TEM picture shows, in addition to the previously found "amorphous" phase, some large cubic pyrite crystals (Fig. 5).

The mean particle size of the pyrite crystals was estimated from the broadening of the x-ray diffraction peaks by using Scherrer's equation ${ }^{30}$ :

$$
D=\frac{\alpha \lambda}{\beta \cos \theta},
$$

where $D$ is the mean particle size, $\alpha$ is a geometric factor (equal to 0.94), $\lambda$ is the $\mathrm{x}$-ray wavelength $(1.5406 \AA$ ), and $\beta$ is the half-width of the diffraction peak. The mean particle sizes so obtained were about $200 \mathrm{~nm}$ for the pyrite crystals, in agreement with the electron micrographs.

Some information on the composition and thermal stability of the prepared nanocomposites was obtained by DSC and TGA. In TGA no considerable weight loss was observed below $180{ }^{\circ} \mathrm{C}$. DSC analyses show exothermic peaks at ca. $225{ }^{\circ} \mathrm{C}$ and $290{ }^{\circ} \mathrm{C}$. Mackinawite and greigite are not stable above $200{ }^{\circ} \mathrm{C}$ near ambient pressure. The only stable compounds in the $\mathrm{Fe}-\mathrm{S}$ system at temperatures above $200{ }^{\circ} \mathrm{C}$ are pyrrhotites and pyrite ${ }^{15,31}$; pyrite is nearly unaffected since it is thermally stable up to ca. $743{ }^{\circ} \mathrm{C}^{31}$ (pieces of a block of a Spanish pyrite crystal, in our hands, decomposed between 570 and $650{ }^{\circ} \mathrm{C}$ ). The most possible reactions at the above-mentioned temperatures are decompositions of mackinawite and greigite to elemental sulfur and iron sulfides such as the various types of pyrrhotites.
Because of the complexity of the system and the large number of possible transformations, it is not possible to clearly identify the exact process. Melting of PEO $\left(T_{m}=67{ }^{\circ} \mathrm{C}\right)$ could not be observed.

\section{Composites prepared with PEO, $\mathrm{FeCl}_{2}$, and $\mathrm{Na}_{2} \mathrm{~S}$ or " $\mathrm{Na}_{2} \mathrm{~S}_{4}$ "}

Other nanocomposites were prepared at room temperature by reaction of $\mathrm{FeCl}_{2}$ with a sodium oligosulfide, $\mathrm{Na}_{2} \mathrm{~S}_{x}$. The sodium oligosulfide was prepared according to the literature by reaction of sodium with elemental sulfur. ${ }^{32} \mathrm{X}$-ray fluorescence analysis resulted in a $\mathrm{S} / \mathrm{Na}$ ratio of $1.95 \pm 0.13$. No elemental sulfur was detected by DSC; i.e., the oligosulfide had the average composition $\mathrm{Na}_{2} \mathrm{~S}_{4}$. It is not evident if the oligosulfide consisted exclusively of tetrasulfide or if it is a mixture of oligosulfides of different stoichiometry.

" $\mathrm{Na}_{2} \mathrm{~S}_{4}$ " was reacted at room temperature with a solution containing $\mathrm{FeCl}_{2}$ and PEO. Instantaneously, a solid precipitated that was filtered and dried (see Experimental section). As revealed by x-ray diffraction, the nanocomposite obviously contained at least two crystalline compounds, but elemental sulfur was the only one that could be identified. No chlorine was detected by $\mathrm{x}$-ray fluorescence analysis.

In transmission electron micrographs, two types of particles were observed: elongated particles (length $100-500 \mathrm{~nm}$, aspect ratio ca. 6) and particles of a round shape (average size ca. $30 \mathrm{~nm}$ ). Elongated particles of similar size were also observed after reaction of $\mathrm{NiCl}_{2}$ and $\mathrm{CuCl}_{2}$ with " $\mathrm{Na}_{2} \mathrm{~S}_{4}$," and crystalline sulfur was also detected in these samples by x-ray diffraction. In contrast, after reaction of $\mathrm{CoCl}_{2}$ with " $\mathrm{Na}_{2} \mathrm{~S}_{4}$," neither elongated particles could be found in transmission electron micrographs nor crystalline sulfur in x-ray diffraction

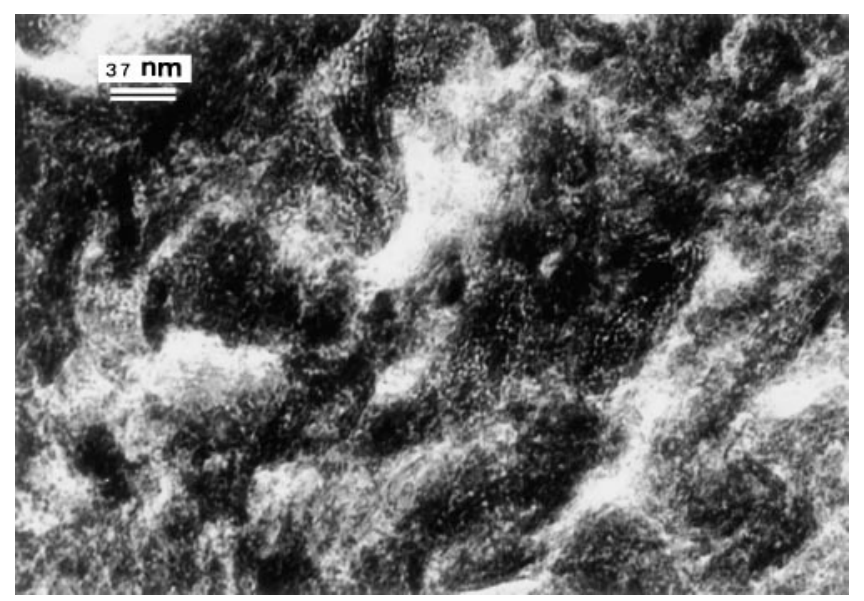

FIG. 3. TEM picture of a nanocomposite that consists of mackinawite and greigite. 
TABLE III. Composition and optical constants $\left(n^{*}=n-i k\right)$ of nanocomposites of poly(ethylene oxide) and iron sulfates prepared from Mohr's salt and NaHS, depending on the reaction time $t$ and reaction temperature $T$ (for experimental conditions, see text). The deviation from the mean value refers to a $95 \%$ confidence level.

\begin{tabular}{cccccc}
\hline \hline$T$ & $t$ & NaHS/Fe & $n$ & $k$ & Crystalline products \\
\hline $75{ }^{\circ} \mathrm{C}$ & $96 \mathrm{~h}$ & 1 & $2.5 \pm 0.2$ & $-0.4 \pm 0.2$ & Mackinawite, greigite \\
$75^{\circ} \mathrm{C}$ & $91 \mathrm{~h}$ & 2 & $2.6 \pm 0.1$ & $-0.76 \pm 0.06$ & Mackinawite, greigite \\
$95{ }^{\circ} \mathrm{C}$ & $69 \mathrm{~h}$ & 2 & $2.52 \pm 0.02$ & $-0.6 \pm 0.1$ & Mackinawite, greigite \\
$95^{\circ} \mathrm{C}$ & $94 \mathrm{~h}$ & 2 & $2.2 \pm 0.1$ & $-0.52 \pm 0.06$ & Mackinawite, greigite \\
$75^{\circ} \mathrm{C}$ & $94 \mathrm{~h}$ & 3 & $2.4 \pm 0.3$ & $-0.9 \pm 0.1$ & Mackinawite, greigite \\
$75^{\circ} \mathrm{C}$ & $140 \mathrm{~h}$ & 3 & $2.5 \pm 0.2$ & $-0.34 \pm 0.02$ & Mackinawite, greigite \\
\hline \hline
\end{tabular}

patterns. It is, therefore, concluded that the elongated objects are elemental, crystalline sulfur.

The particles with round shape after reaction of $\mathrm{FeCl}_{2}$ with " $\mathrm{Na}_{2} \mathrm{~S}_{4}$ " are attributed to iron sulfides. In the composites with nickel, round particles of $60-150 \mathrm{~nm}$ diameter, and in those with copper of 20-70 nm diameter were visible, while in the composite with cobalt the particle diameters were below $10 \mathrm{~nm}$.

The composites with iron, nickel, and copper particles showed in DSC plots two exothermic signals between 112 and $119^{\circ} \mathrm{C}$, while no signals were observed for the composite with cobalt sulfides. We suggest that these signals are due to the presence of elemental sulfur since we measured for bulk elemental sulfur peaks at 112 and $122{ }^{\circ} \mathrm{C}$. According to the literature, ${ }^{33}$ sulfur undergoes phase transitions at 95.6 and $110-120{ }^{\circ} \mathrm{C}$, the exact position depending on the heating rate. ${ }^{33}$ In particular, the transition at $95.5^{\circ} \mathrm{C}$ is sluggish ${ }^{34}$ and probably occurs under our conditions (heating rate $10{ }^{\circ} \mathrm{C} / \mathrm{min}$ ) at higher temperatures. That elemental sulfur is present in the composites with iron, nickel, and copper sulfides, but not in those with cobalt sulfides, is in agreement with the above-mentioned x-ray and TEM analyses.

The composite with iron sulfides consisted of ca. $10 \% \mathrm{w} / \mathrm{w}$ PEO. The $\mathrm{S} / \mathrm{Fe}$ ratio was $5.1 \pm 0.2$, indicating that the amount of elemental sulfur in the com-

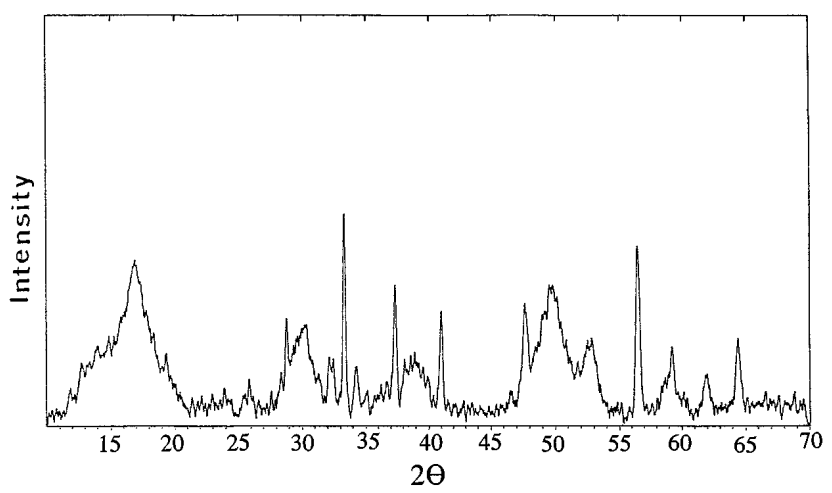

FIG. 4. X-ray diffractogram of a nanocomposite that contains, in addition to mackinawite and greigite, pyrite and was prepared at $95{ }^{\circ} \mathrm{C}$ for $48 \mathrm{~h}$ with $\mathrm{H}_{2} \mathrm{~S}$ and $\mathrm{NaOH} / \mathrm{Fe}=2.4$. posite is large. The refractive index in these composites was close to those with FeS (1.8-1.9), i.e., far below the highest refractive indices of the materials prepared from Mohr's salt and $\mathrm{H}_{2} \mathrm{~S}$ or NaHS.

For comparison, composites of FeS and PEO were prepared at room temperature by addition of $\mathrm{Na}_{2} \mathrm{~S}$ to a PEO solution containing $\mathrm{FeCl}_{2}$. Samples with a PEO content of $5-20 \% \mathrm{w} / \mathrm{w}$ were prepared by variation of the $\mathrm{Fe}^{2+} / \mathrm{PEO}$ ratio in the reaction solution. The average particle size was $5-8 \mathrm{~nm}$, and there was no indication for the presence of elemental sulfur by x-ray diffraction, DSC, or TEM. The refractive index of the resulting materials was $1.8-1.9$ at 632.8 and $1295 \mathrm{~nm}$, i.e., clearly below those of the nanocomposites with the highest refractive indices described above. For this reason, the materials were not characterized further.

\section{DISCUSSION}

As expected, the chemistry of the formation of iron sulfides is complex and depends on many parameters, such as iron and sulfur sources, temperature, and reaction time. Usually it is hardly possible to predict the composition of the iron sulfides. The number of experiments to study the influence of all parameters systematically is

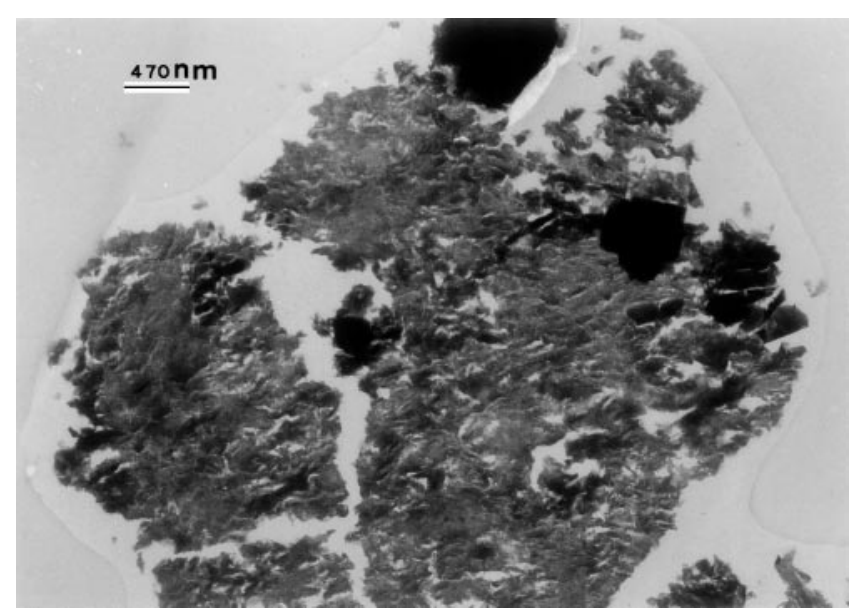

FIG. 5. TEM picture of a composite that consists of mackinawite, greigite, and pyrite. 
so numerous that it exceeds our resources. Instead, we attempted a selection of a limited number of experiments that could lead to a "local refractive index maximum."

Composites with refractive indices of 1.8-2.0 at 1295 and $632.8 \mathrm{~nm}$ can be readily prepared under various conditions. Materials with refractive indices of 2.5-2.8 (at least at $1295 \mathrm{~nm}$ ) were prepared with Mohr's salt which seems to be more favorable for the preparation of high refractive index materials than $\mathrm{FeCl}_{2}$ or $\mathrm{FeSO}_{4}$. This might be due to the presence of the ammonium ions in Mohr's salt. As mentioned in the introduction, the formation of the different iron sulfides can depend on the $\mathrm{pH}$ value. The ammonium ions could influence the $\mathrm{pH}$ values in certain stages of iron sulfide formation.

The highest refractive indices were obtained with reaction times of several days and elevated reaction temperatures. The samples with the highest refractive indices contain mackinawite and greigite. Considering a refractive index of 2.5 in the composite, it is likely that one or both of these compounds have a refractive index above 3 at 1295 and probably $632.8 \mathrm{~nm}$.

The density of elemental sulfur is $2.07 \mathrm{~g} / \mathrm{cm}^{3},{ }^{1}$ of pyrite $5.0 \mathrm{~g} / \mathrm{cm}^{3},{ }^{1}$ of marcasite $4.87 \mathrm{~g} / \mathrm{cm}^{3},{ }^{1}$ of troilite $4.74 \mathrm{~g} / \mathrm{cm}^{3},{ }^{1}$ of greigite $4.05 \mathrm{~g} / \mathrm{cm}^{3},{ }^{35}$ and of magnetite $5.18 \mathrm{~g} / \mathrm{cm}^{3} .{ }^{1}$ For PEO we measured a density of $1.27 \mathrm{~g} /$ $\mathrm{cm}^{3}$, in agreement with the literature. ${ }^{36}$ The densities of two powders containing $1.6 \% \mathrm{w} / \mathrm{w}$ (composite II) and $4.1 \% \mathrm{w} / \mathrm{w}$ PEO (composite III) were $3.16 \mathrm{~g} / \mathrm{cm}^{3}$ and $3.53 \mathrm{~g} / \mathrm{cm}^{3}$, respectively. Composite II contained elemental sulfur, magnetite, and greigite, composite III elemental sulfur and greigite. Of course, both composites could contain additional compounds that are amorphous. Assuming that composite II consisted of elemental sulfur, greigite, and PEO, composite II contained $20 \% \mathrm{w} / \mathrm{w}$ elemental sulfur. This value is of the same order of magnitude as the $8-11 \%$ estimated from the $\mathrm{S} / \mathrm{Fe}$ ratio. $20 \% \mathrm{w} / \mathrm{w}$ sulfur would correspond to $28 \% \mathrm{v} / \mathrm{v}$, and $4 \% \mathrm{v} / \mathrm{v}$ would then be represented by PEO and $68 \%$ $\mathrm{v} / \mathrm{v}$ by greigite. If the only iron species in composite III was greigite, the elemental sulfur content was $5 \% \mathrm{w} / \mathrm{w}$ $(10 \% \mathrm{v} / \mathrm{v})$; if magnetite was the only iron species the sulfur content was $29 \% \mathrm{w} / \mathrm{w}(56 \% \mathrm{v} / \mathrm{v})$, i.e., composite III also contains a significant amount of sulfur.

A high volume fraction of elemental sulfur could decrease the refractive index of the composite below 2.0 (the refractive index of elemental sulfur is 1.96). ${ }^{1}$ Indeed, in the materials with the highest refractive indices, no elemental sulfur was detected with x-ray diffraction, DSC, or TEM.

The samples with the highest refractive indices most likely contain pores that may take up about $10 \%$ of the total volume. One could try to avoid pores by increasing the polymer fraction. If there is, however, too much polymer in the composite, its refractive index will be lowered. Here we selected usually a polymer content of roughly $10 \% \mathrm{v} / \mathrm{v}$ polymer. We consider this an acceptable compromise for the endeavor to decrease the polymer and the pore fraction.

As expected from the literature (see Introduction), pyrite, which was speculated to have a high refractive index, is difficult to prepare under our experimental conditions, i.e., at atmospheric pressure below $100{ }^{\circ} \mathrm{C}$. Samples containing pyrite as the only iron salt could not be obtained. The refractive indices of the samples containing pyrite, mackinawite, and greigite are of the same order as those of the samples containing mackinawite and greigite but not pyrite. This indicates that either the refractive index of pyrite is similar to that of greigite and mackinawite, or that the pyrite fraction is too low to influence the composite's refractive index markedly.

We hoped that the use of oligosulfides might give rise to pyrite synthesis, but such crystals were not observed in the corresponding composites. At least a part of the oligosulfides decomposed, leaving elemental sulfur. As a consequence, it is not surprising that these composites did not show the highest refractive indices. It cannot be excluded that iron oligosulfides also form, but if so, they do not enhance the refractive index of the composite significantly.

As far as we know, only the refractive indices of PEO-PbS composites (around 3$)^{4}$ have been reported to be higher than those of the highest refractive index composites prepared here. The PEO-PbS composites contain ca. 50\% v/v PEO. In contrast to the composites with iron sulfides, however, the composition in the $\mathrm{PEO} / \mathrm{PbS}$ nanocomposites can be directed by the ratios of the components in solution only in a limited way: "excesses" of PEO or PbS remain in solution. We suggest that the different precipitation behavior in the iron and the lead systems is due to a different coordination capability of PEO to substances in these systems.

As in the case of the PEO-PbS composites, the samples with iron sulfides are not transparent; i.e., they appear dark brown. The small size of the filler leads to a strong reduction of light scattering, as is evident from Eq. $(7)^{37}$ :

$$
\frac{I}{I_{0}}=\exp \left[-\frac{3 \phi_{p} x r^{3}}{4 \lambda^{4}}\left(\frac{n_{p}}{n_{m}}-1\right)\right],
$$

which is valid for spheric particles with radius $r$ and refractive index $n_{p}$ dispersed in a matrix with refractive index $n_{m} ; I$ is the intensity of the light passing the sample, $I_{0}$ the intensity of the light that would pass the sample without scattering, $\phi_{p}$ is the volume fraction of the particles, $\lambda$ is the wavelength of light, and $x$ the optical path length. For a composite containing $90 \% \mathrm{v} / \mathrm{v}$ spheric particles $\left(\phi_{p}=0.9\right)$, and assuming $r=10 \mathrm{~nm}, n_{m}=1.5, n_{p}=4, \lambda=700 \mathrm{~nm}$, and $x=$ $100 \mu \mathrm{m}$, the intensity loss due to scattering is ca. $0.05 \%$. 
The absorption coefficients of typically -0.4 to -1 indicate that absorption is responsible for the opacity rather than light scattering.

\section{CONCLUSIONS}

Composites of iron sulfides and PEO can be prepared by co-precipitation. The composition of the inorganic fraction depends on the reaction parameters, such as inorganic reactants, reaction time, and temperature. Usually two or three crystalline iron sulfide species and, occasionally, elemental sulfur and iron oxides were detected by $\mathrm{x}$-ray diffraction analysis.

Samples with refractive indices on the order of 2 at 632.8 and $1295 \mathrm{~nm}$ are readily obtained. For higher refractive indices, a high amount of elemental sulfur in the composite should be avoided since this leads to moderate refractive indices. Suitable reactants for the preparation of composites with refractive indices above 2 are Mohr's salt and $\mathrm{H}_{2} \mathrm{~S}$ or NaHS. Sodium oligosulfides are less suitable because they lead to elemental sulfur.

Mackinawite and greigite (or "amorphous FeS") strongly enhance the refractive index of the composites. This is probably also true for pyrite. To prepare composites with a pyrite content as high as possible, a reaction temperature as high as possible, (i.e., near the boiling temperature of water) should be selected.

To obtain materials with highest refractive indices, pores should be avoided since air present in the pores decreases the refractive index of the composite. On the other hand, a complete absence of pores achieved with relatively high polymer contents will lead also to low refractive indices since the refractive index of organic polymers is clearly below that of high refractive index iron sulfides present in the composite. Hence, an optimum polymer content has to be found, which seems to be somewhere around $10 \% \mathrm{v} / \mathrm{v}$. To date, it seems to be possible to prepare nanocomposites with iron sulfides that exhibit refractive indices of ca. 2.8.

\section{ACKNOWLEDGMENTS}

We gratefully acknowledge financial support from the Swiss Priority Program in Materials Research and the Student Exchange Fund of the ETH-Council. Experimental support by Martin Colussi, Dr. René Müller, and PD Dr. Martin Müller is appreciated. We also acknowledge the help of Andreas Widler in performing some experiments and Professor Dr. Terry Seward for useful discussions.

\section{REFERENCES}

1. Handbook of Chemistry and Physics, edited by R. C. Weast (CRC Press, Boca Raton, FL, 1985).

2. Polymer Handbook, edited by J. Brandrup and E. H. Immergut (John Wiley and Sons, New York, 1989).
3. Handbook of Optical Constants of Solids, edited by E. D. Palik (Academic Press, Orlando, FL, 1985).

4. M. Weibel, W. Caseri, U.W. Suter, H. Kiess, and E. Wehrli, Polym. Adv. Technol. 2, 75 (1991)

5. L. Zimmermann, M. Weibel, W. Caseri, and U. W. Suter, J. Mater. Res. 8, 1742 (1993).

6. T. Kyprianidou-Leodidou, W. Caseri, and U.W. Suter, J. Phys. Chem. 98, 8992 (1994).

7. L. Zimmermann, M. Weibel, W. Caseri, U.W. Suter, and P. Walther, Polym. Adv. Technol. 4, 1 (1993).

8. R. Dasbach, G. Willeke, and O. Blenk, Mater. Res. Soc. Bull. 18, 10 (1993)

9. R. H. Morf and H. Kiess, Proceedings of the 9th Photovoltaic Solar Energy Conference (Freiburg, Germany, 1989).

10. E. J. Gilles and G. M. Bancroft, Geochem. \& Cosmochem. Acta 49, 979 (1985).

11. M. M. Hyland and G. M. Bancroft, Geochem. \& Cosmochem. Acta 53, 367 (1989).

12. D. J. Vaughan and J. Craig, Mineral Chemistry of Metal Sulfides (Cambridge University Press, 1978).

13. J. W. Morse, F. J. Millero, J. C. Cornwell, and D. Rickard, Earth Sci. Rev. 24, 1 (1987)

14. R. A. Berner, Am. J. Sci. 265, 773 (1967).

15. P. Taylor, Am. Mineral. 65, 1026 (1980).

16. D. T. Rickard, Am. J. Sci. 275, 636 (1975).

17. R. A. Berner, Am. J. Sci. 268, 1 (1970).

18. R. A. Berner, Geochem. Cosmochem. Acta 48, 605 (1984).

19. P. Taylor, T. E. Rummery, and D. G. Owen, J. Inorg. Nucl. Chem. 41, 595 (1979)

20. M. Uda, Am. Mineral. 50, 1487 (1965).

21. S. Takeno, H. Zoka, and T. Niihara, Am. Mineral. 55, 1639 (1970).

22. M. A. A. Schoonen and H.L. Barnes, Geochem. Cosmochem. Acta 55, 1495 (1991).

23. M. A. A. Schoonen and H.L. Barnes, Geochem. Cosmochem. Acta 55, 1505 (1991).

24. M. A. A. Schoonen and H.L. Barnes, Geochem. Cosmochem. Acta 55, 3491 (1991).

25. M. A. A. Schoonen, Mechanisms of Pyrite and Marcasite Formation from Solutions between 25 and $300{ }^{\circ} \mathrm{C}$ (Ph.D. Dissertation, The Pennsylvania State University, 1989).

26. M. B. Roberts, A. L. Walker, and A. S. Buchanan, Mineral. Deposita 4, 18 (1969).

27. J. B. Murowchick and H.L. Barnes, Geochem. Cosmochem. Acta 50, 2615 (1986).

28. E. J. A. Pope, M. Asami, and J.D. Mackenzie, J. Mater. Res. 4, 1018 (1989)

29. E. J. A. Pope, M. Asami, and J. D. Mackenzie, in Multicomponent Ultrafine Microstructures, edited by L. E. McCandlish, D. E. Polk, R. W. Siegel, and G. H. Kear (Mater. Res. Soc. Symp. Proc. 132, Pittsburgh, PA, 1989), p. 105.

30. A. Taylor, X-ray Metallography (John Wiley and Sons, New York, 1961), p. 674.

31. S. D. Scott, Sulfide Mineralogy, Mineralogical Society of America short course notes vol. 1, edited by P. H. Ribbe (B. J. Wuensch, Washington, 1975).

32. C. Z. Draves and H. V. Tartar, J. Am. Chem. Soc. 48, 1527 (1926).

33. Römpp Chemie Lexikon, edited by J. Falbe and E. H. M. Regitz (Georg Thieme, Stuttgart, 1992).

34. F. A. Cotton and G. Wilkinson, Anorganische Chemie (Verlag Chemie, Weinheim, 1989).

35. S. A. Williams, Am. Mineral. 53, 2087 (1968).

36. Encyclopedia of Polymer Science and Engineering, edited by H. F. Mark, N.M. Bikales, C. G. Overberger, G. Menges, and J. I. Kroschwitz (John Wiley and Sons, New York, 1987).

37. B. M. Novak, Adv. Mater. 5, 422 (1993). 